\title{
Ruling the Hive: An Interview with Melody Eötvös
}

\author{
Simone Maurer
}

Melody Eötvös (b. 1984) was born in the Southern Highlands, NSW, Australia. Her work draws on both multimedia and traditional instrumental contexts, and makes substantial extra-musical references to philosophical, biological and ancient topics as well as her sustained interest in late nineteenth-century life and literature.

Eötvös is Lecturer in Composition and Aural Skills at the Melbourne Conservatorium of Music, and holds a Doctor of Music from the Jacobs School of Music at Indiana University and a Master of Music from the Royal Academy of Music in London. She has studied with a variety of composers across the globe including Gerardo Dirié in Australia, Simon Bainbridge in the United Kingdom and, most recently, with Claude Baker, David Dzubay, P.Q. Phan and Aaron Travers in the United States. She has also studied electronic music with Jeffrey Hass, John Gibson and Alicyn Warren.

Recent accolades include the Soundstream National Composer Award (2012), the Gallipoli Songs composition competition (2014), the Virginia B. Toulmin Foundation Orchestral Commission (2015), the Seattle Metropolitan Chamber Orchestra International Composition Competition (2016), and the orchestral prize for the Red Note Music Festival (2017). She was a finalist in the Orchestral Music category of the 2019 APRA-AMCOS Art Music Awards and 
has had her music performed by ensembles and orchestras such as the London Sinfonietta, the BBC Singers, the Australian String Quartet, the Tasmanian Symphony Orchestra, the American Composers Orchestra, and the Philadelphia Orchestra.

Eötvös's Ruler of the Hive (2018) is a twenty-eight-minute work for orchestra and narrator in five movements: I. 'Emilia'; II. ‘Beatrice'; III. 'Helena'; IV. 'Isabella'; V. 'Rosalind.' The work was featured in a Shakespeare-themed concert performed by the Melbourne Symphony Orchestra with Johannes Fritzsch (conductor) and Pamela Rabe (narrator) on 22 April 2021 at Hamer Hall, Arts Centre Melbourne.

There is an enormous variety of women characters in Shakespeare's plays. Ruler of the Hive uses five female characters and monologues: Emilia from Othello, Beatrice from Much Ado About Nothing, Helena from All's Well That Ends Well, Isabella from Measure for Measure, and Rosalind from As You Like It. How did you choose these characters and texts?

Originally, I only chose three texts to work with: Helena, Emilia and Isabella. I met with Pamela Rabe after having done some draft work during the same trip to Australia that I also had a workshop with the Tasmanian Symphony Orchestra for the material I had written so far. This is something that never really happens with a professional orchestra, so I was exceptionally lucky to get this little preview of the music I had written up until that point! After meeting with Pamela and discussing the texts that I had chosen, and learning a significant amount of new information about Shakespeare whilst gaining a lot of insight into the works I was focusing on, I realised that I needed more of these monologues to use in my piece. I very readily relied on Pamela's advice at this point, and she offered several other monologues to consider. As for choosing the final monologues, I wanted the most spunky, heart-felt, angry and emotionally driven texts I could find.

You mentioned that it is rare to workshop a piece with a professional orchestra-did the orchestra or conductor help workshop the piece at that time as well? And what usually happens when writing for a professional orchestra? How much interaction or freedom do you have?

Yes, the Tasmanian Symphony Orchestra had organised for a separate workshop with the entire orchestra over a few days in Hobart-probably a good five months before the scheduled performance. It was incredible, and Marko Letonja, who was the conductor for the performance, was there so he was able to get a great idea of the trajectory of the piece. And I, of course, was able to test out about nine minutes of music. Orchestras are expensive organisations to run, so the fact that I had access to those early rehearsals was a massive blessing. In terms of interaction, yes, it is normal to get a little feedback from the players and conductor but having a dedicated workshop session allowed for so much more of an exchange with everyone. It really informed the outcome of the final piece.

In terms of the piece's title, Ruler of the Hive, you have previously mentioned that the work brings the five women together, implying that they have more control (and ruling) of their own environments. What inspired the title?

The inspiration came from the heart of Shakespeare. The Tasmanian Symphony Orchestra had requested a Shakespeare-themed piece for orchestra and narrator, and I had a few other ideas (such as using modern stories that were based on original Shakespeare works), but they 
very much supported the female monologue idea the most. So far as the title goes, I take great pains when choosing titles for my pieces and they must fit perfectly with the concept as well as with the music that I have written so far (if I start writing the piece before choosing the title). With Ruler of the Hive, I decided that I needed to find a parallel in the animal kingdom where females are in charge (because we certainly cannot use our own species), as I deep down felt the women in the texts I had chosen were also in charge, or taking charge of their lives and roles in some way.

Your musical style has been described as having 'old pagan flavours, but with new mindset and expression.' I was struck by the lush colours, layers and textures of your orchestration. Furthermore, the orchestration did not just complement the characters, but also expanded on them with long sections of just orchestra. How did you approach composing with Shakespeare's text and the characters in mind?

Composing with text that was not going to be sung and woven into the musical texture of the piece was quite a challenge. I had to decide whether I was going to create a dialogue between the narrator and the orchestra or whether it would be more statement-like with the orchestra supporting in an accompanying texture. In the end, I used both methods, depending on the nature of the monologue. For the character of the music, I did quite a bit of listening to Renaissance music, and I think the sound of that genre soaked into my subconscious very effectively. I think that the more I enjoy listening to something the easier its characteristics are absorbed into my composition palette. Anyway, that was very important for this work as I wanted the character of the music to reach out from the original time and place these works were written. For the individual women, I relied on the emotional content of their monologues to dictate that element of the music, in a very programmatic-music-type way.

In the programme notes, you mention your love of Renaissance music. Were you introduced to Renaissance music in a particular way, or was it something that you discovered during your education?

I suppose I heard a little of it when I was growing up - my parents are both music teachers and only played classical music or early jazz in the house; so, some later Renaissance music must have been in there somewhere. As an adult though, it was when I took a Latin American music history class in my undergraduate degree that I really was exposed to it properly, and from the South American works I found my way to the European ones. There was also a huge 'ah-ha' moment when I stumbled on The Dowland Project, which is a modern performers' perspective and interpretation of John Dowland's works. They are incredibly insightful and refreshing covers of the original works and I often listen to them even when not seeking inspiration.

You also wrote that you enjoy 'working with modes and symmetrical pitch formations.' Can you speak more to this?

There are some very effective extra-musical art forms that have excellent cross-over applications with music - architecture is another geometry-related form that I have tinkered with before (and I used to draw up detailed architectural floor plans/blueprints as a kid!). I also have a huge respect for geometry in that alongside mathematics it is one of the universal truths! So far as working with symmetrical forms and modes in my music, there is much more exploration 
and experimentation that I look forward to doing in the future, which is why I love working with these forms-there is so much potential for future expansions of the materials without 'ripping oneself off'. I guess I also feel that bringing these forms into my music adds an aspect of control and order that balances out the mostly 'intuitive' approach I take in composing.

As a flute player, I was particularly struck by your upper woodwind writing. How would you describe your approach to orchestral writing? Do you have any favourite instrument combinations or orchestral writing techniques?

I love writing for orchestra. It has been a passion of mine for over ten years now and every piece I write is so easy to manifest! It is my ultimate ensemble, I think. Loud, soft, violent, calm, chamber, solo, homogenous strings, random combinations, any colouration imaginable really. My actual approach varies—if I write the piece quickly, I will likely have used a short score. Most recently, I completed a piece where the entire short score had been written in the strings, then I expanded it out from there with the actual orchestration. For me, that process worked, streamlined everything, and was the most efficient use of my time (which I do not usually have much of!). Alternatively, I could write passages at the piano and orchestrate out from there, or I will write straight into a full orchestral score (the best option!). As for favourite techniques or colours, it really depends on what I am writing. I have been favouring more rhythmically driven music lately, but even so, I always try to blend several instruments from different sections into interesting colours, no matter the atmosphere or 'vibe' of the music.

\section{What did you learn from collaborating with Pamela Rabe?}

A lot! She is a fountain of knowledge and is very generous with her time and sharing what she knows. I also learnt that it is important to rely on other people when participating in a collaboration like this work was (such as asking Pamela to record the monologues before I started composing, and using those recordings for timings as well as Pamela's interpretation of the texts), and that I should always be open to the possibility that my perspective on something is most likely incomplete!

Ruler of the Hive was premiered by the Tasmanian Symphony Orchestra with Marko Letonja (conductor) and Pamela Rabe (narrator) at Federation Concert Hall, Hobart, on 4 August 2018 and then performed three more times during the MSO's 2021 season. How did each performance differ?

Well, the world premiere in Tasmania was very interesting. Amazing, but interesting. The day before I was still writing new music for the fifth movement due to a balance issue between the monologue and the music. Pamela was amplified, yet somehow it was not enough to project her voice through the musical texture. So, there I was, in my hotel room with my thentwo-year-old son sleeping beside me, writing brand new music! After the world premiere, I was able to look a little closer at that passage and improve on it even more, which is now the final version of that movement. There was a second performance in Queensland by the conservatorium orchestra, conducted by Johannes Fritzsch with five different narrators-all students from the drama school there in Southbank (Brisbane). Working with the university orchestra at my alma mater was so thrilling, and seeing those five young women adapt to the roles they took on as well as work with a full orchestra was amazing. Then, this year with 
the Melbourne Symphony Orchestra, it was just looked so easy for them, being the incredible orchestra that they are. The feedback I received from many players was heart-warming. This performance in Melbourne was probably the best and most consistent as we had figured out all the balance issues, the piece was complete, and Pamela returned to do the narration having already worked with the music before. So, it was perfect!

I attended the concert at Hamer Hall, which was the first time I had visited the Arts Centre Melbourne since the pandemic started. Has COVID-19 impacted or influenced your composing over the past year?

Somewhat-all of my orchestral performances were postponed, but it actually gave me more time to work on my overloaded composing schedule and I had up to eight months extra on certain pieces which was a lifesaver. I also picked up several 'COVID-friendly' commissions (such as the Canberra Symphony Orchestra miniseries and the Australian Voices choral miniatures) which were fun and easy to complete.

\section{Are you currently working on any new compositions or projects?}

Yes! The main projects include working on a solo viola piece for the Australian National Academy of Music Set-an initiative in which sixty-seven Australian composers will work in close partnership with ANAM's sixty-seven musicians to create sixty-seven new solo/duo Australian works due to be premiered in 2021—a piano sonata for Alex Raineri, as well as a string quartet and voice work for the Flinders Quartet later in the year. ${ }^{1}$

Is there a type of composition (for a combination of instruments or a particular ensemble) or a compositional idea that you have not yet, but would like to write for?

Every few months or so I have a recurring dream about an opera that I have written (but yet to write) - it occurs in several alternate realities. Haha! It happens in a giant warehouse (like a Universal Studios one) and the entire space is the opera stage, multiple levels, multiple rooms. And there are elevators and moving walkways everywhere that the audience uses to actually interact and get close to the performers. To top that, the audience can pop on virtual-reality goggles to experience an alternate reality score and performance in the same time frame as the real world one. I am not sure what the topic is, but I am pretty sure it involves historical fiction from 1899 or around that time stamp. Crazy ambitious, but it would be incredible!

\footnotetext{
About the Author

Simone Maurer is a PhD researcher in contemporary classical flute performance and music psychology. Her thesis investigates the embodied cognition of solo flute players in performance. Simone is also a music and dance tutor at the Faculty of Fine Arts and Music, University of Melbourne.
}

\footnotetext{
${ }^{1}$ Due to COVID-19 restrictions, the ANAM Set was postponed until 2022. The piano sonata was performed in December 2021, but the Flinders Quartet work was rescheduled to May 2022.
} 